\title{
Testosterone 5 $\alpha$-Reductase Inhibitory Active Constituents of Piper nigrum Leaf
}

\author{
Noriko Hirata, ${ }^{a}$ Masashi Tokunaga, ${ }^{a}$ Shunsuke Naruto, ${ }^{a}$ Munekazu Innuma,,${ }^{b}$ and \\ Hideaki MATSUDA $*, a$ \\ ${ }^{a}$ School of Pharmaceutical Sciences, Kinki University; 3-4-1 Kowakae, Higashiosaka, Osaka 577-8502, Japan: and \\ ${ }^{b}$ Gifu Pharmaceutical University; 5-6-1 Mitahora-higashi, Gifu 502-5858, Japan. \\ Received July 10, 2007; accepted August 29, 2007
}

Previously we reported that Piper nigrum leaf extract showed a potent stimulation effect on melanogenesis and that (-)-cubebin (1) and (-)-3,4-dimethoxy-3,4-desmethylenedioxycubebin (2) were isolated as active constituents. As a part of our continuous studies on Piper species for the development of cosmetic hair-care agents, testosterone $5 \alpha$-reductase inhibitory activity of aqueous ethanolic extracts obtained from several different parts of six Piper species, namely Piper nigrum, P. methysticum, P. betle, P. kadsura, P. longum, and P. cubeba, were examined. Among them, the extracts of $P$. nigrum leaf, $P$. nigrum fruit and $P$. cubeba fruit showed potent inhibitory activity. Activity-guided fractionation of $P$. nigrum leaf extract led to the isolation of 1 and 2 . Fruits of $P$. cubeba contain 1 as a major lignan, thus inhibitory activity of the fruit may be attributable to 1 . As a result of further assay on other known constituents of the cited Piper species, it was found that piperine, a major alkaloid amide of $P$. nigrum fruit, showed potent inhibitory activity, thus a part of the inhibitory activity of $P$. nigrum fruit may depend on piperine. The $5 \alpha$-reductase inhibitory activities of 1 and piperine were found for the first time. In addition, the $P$. nigrum leaf extract showed in vivo anti-androgenic activity using the hair regrowth assay in testosterone sensitive male C57Black/6CrSlc strain mice.

Key words Piper nigrum; testosterone $5 \alpha$-reductase; cubebin; piperine; anti-androgenic activity; hair regrowth

Because of the increase of the elderly population, a larger fraction of people are now afflicted with alopecia and/or gray hair. Thus the market for hair growth agents, hair-dye, and anti-gray hair agents is growing. Testosterone $5 \alpha$-reductase catalyzes the conversion of testosterone to an active androgen, dihydrotestosterone, which binds to androgen receptors and shows various hormonal actions. An excessive accumulation of dihydrotestosterone is recognized as leading to male pattern baldness and benign prostatic hyperplasia. ${ }^{1,2}$ Treatment with a testosterone $5 \alpha$-reductase inhibitor would be expected to lead to a decrease of dihydrotestosterone concentration in many tissues, and may be useful for protection against alopecia. On the other hand, gray hair is caused by aging, decrement of melanocytes by environmental stress, and decrement of the melanogenesis. ${ }^{3,4)}$ Therefore, it was expected that agents which exhibit both melanogenesis stimulation activity and testosterone $5 \alpha$-reductase inhibitory activity may be desirable ingredients of hair-care cosmetic products for prevention of gray hair and alopecia. During the course of our screening program using cultured murine B16 melanoma cells for the development of gray hair prevention agents from natural resources, we found that extracts of some Piper species (Piperaceae) showed a potent stimulation effect on melanogenesis without any effects on cell proliferation, and two lignans, (-)-cubebin (1) and (-)-3,4-dimethoxy-3,4desmethylenedioxycubebin (2), were isolated as active constituents from the leaves of Piper nigrum L. ${ }^{5-7)}$ With the expectation that we might find new desirable agents from Piper species to prevent gray hair and alopecia as described above, the testosterone $5 \alpha$-reductase inhibitory activity of $50 \%$ ethanolic extracts obtained from several different parts of six Piper species (P. nigrum L., P. methysticum Forst., P. betle L., P. kadsura (Cногу) Онші, P. longum L., and P. cubeba L.) was examined. This paper deals with the screening results of in vitro testosterone $5 \alpha$-reductase inhibitory activity of Piper species, the activity-guided fractionation of $P$. nigrum leaf extract led to the isolation of active lignans, $\mathbf{1}$ and $\mathbf{2}$, and the in vivo anti-androgenic activity of the leaf extract.

\section{MATERIALS AND METHODS}

Plant Materials Several different parts of the six Piper species named above were the same samples described in the previous paper. ${ }^{7}$ Fifty percent ethanolic extracts of each airdried and powdered material of Piper plant were also the same samples described that paper. ${ }^{7}$ Methanolic extracts of $P$. nigrum leaf were obtained according to the previous paper. ${ }^{5)}$

Reagents Testosterone and ethinylestradiol were purchased from Wako Pure Chemical Industries, Ltd. (Osaka, Japan). Oxendolone (Prostetine ${ }^{\circledR}$ ) was purchased from Takeda Chemical Industries Ltd. (Osaka, Japan). Piperine was purchased from Sigma (St. Louis, MO, U.S.A.). Other chemical reagents were reagent grade and were purchased from Wako Pure Chemical Industries, Ltd. unless otherwise noted.

Animals Male SD strain rats (6 weeks of age) and male C57Black/6CrSlc strain mice (7 weeks of age) were purchased from Japan SLC (Shizuoka, Japan). They were maintained in an air-conditioned room with lighting from 7 a.m. to 7 p.m. The room temperature (about $23^{\circ} \mathrm{C}$ and humidity (about $60 \%$ ) were controlled automatically. Laboratory pellet chows (Labo MR Stock and Labo R stock, Nihon Nosan Kogyo Co., Ltd., Tokyo, Japan) and water were freely available.

Assay for Inhibition of Testosterone $5 \alpha$-Reductase Activity Testosterone $5 \alpha$-reductase was prepared from the liver of rats (6 weeks of age) according to the method of Imai. ${ }^{8)}$ Inhibition assay of testosterone $5 \alpha$-reductase was performed according to the method described by $\mathrm{Ibata}^{9)}$ as in 
our previous papers. ${ }^{10-12)} \mathrm{IC}_{50}$ values were graphically calculated from the inhibition percent values at several concentrations.

Hair Regrowth after Shaving in Testosterone-Treated C57Black/6CrSlc Mice According to the method described by Yokoyama ${ }^{13)}$ with minor modification, the dorsal hair of mice ( 7 weeks of age, one group using 8-10 mice) was shaved with electric hair clippers. Beginning the next day, $100 \mu \mathrm{l}$ of testosterone solution $(0.05 \%$ in ethanol) was applied topically to the shaved dorsum once a day for $28 \mathrm{~d}$ except the control group with a pipette and a polypropylene disposable tip. After $30 \mathrm{~min}$ of testosterone treatment, $100 \mu \mathrm{l}$ of the following sample solutions were applied topically to the shaved dorsum once a day for $28 \mathrm{~d}$ in a similar way. Sample solutions in the experiment shown in Fig. 2A: (1) $80 \%$ ethanol as control, (2) $2 \%$ oxendolone solution in $80 \%$ ethanol. Sample solutions in the experiment shown in Fig. 2B: (3) ethanol as control, (4) $2 \%$ and $5 \%$ solution of methanolic extract of $P$. nigrum leaf in ethanol.

The hair regrowth at 13, 16, 19, 22, 25 and $28 \mathrm{~d}$ after beginning of topical application was calculated using the following score: score 0: no hair growth observed; score 1: less than 20\% growth observed; score 2: $20 \%$ to less than $40 \%$ growth observed; score 3: $40 \%$ to less than $60 \%$ growth observed; score $4: 60 \%$ to less than $80 \%$ growth observed; score 5: $80 \%$ to $100 \%$ growth observed.

Statistical Analysis The experimental data were tested

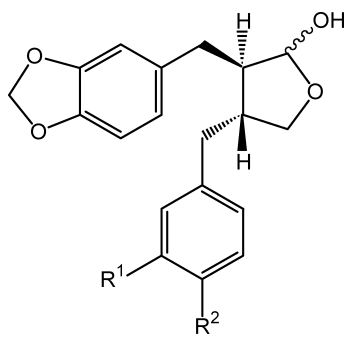

$$
\begin{array}{ll}
1 & \mathrm{R}^{1} \mathrm{R}^{2}: \mathrm{OCH}_{2} \mathrm{O} \\
2 & \mathrm{R}^{1}, \mathrm{R}^{2}: \mathrm{OCH}_{3}
\end{array}
$$

Fig. 1. Chemical Structures of Lignans $\mathbf{1}$ and $\mathbf{2}$

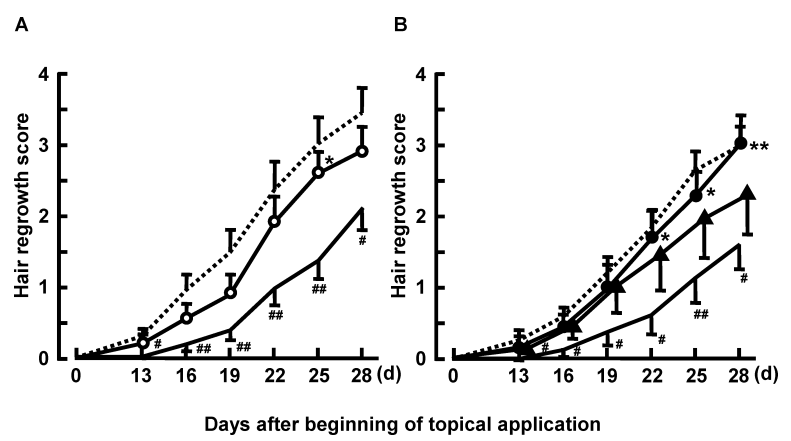

Fig. 2. Effect of Methanolic Extract of Piper nigrum Leaf and Oxendolone on Hair Regrowth after Shaving in Testosterone-Treated C57BL/6CrSlc Mice

A: Control (---), testosterone-treated control (-) and $2 \%$ oxendolone solution $(\bigcirc)$ B: Control (--) and testosterone-treated control (-). 2\% Solution (A) and 5\% solution (-) of methanolic extract of P. nigrum leaf. The regrowth after the start of topical application was calculated by scoring. Each point represents the mean \pm S.E. of 10 to 12 mice. Significantly different from the control group at $\# p<0.05$, \# $p<0.01$. Significantly different from the testosterone-treated control group at $* p<0.05, * * p<0.01$. for statistical significance using Bonferroni/Dunn's multiple range test method.

Extraction, Fractionation and Isolation The powdered dry leaves $(500 \mathrm{~g})$ of $P$. nigrum were extracted with $\mathrm{MeOH}$ (51×3 times) for $1 \mathrm{~h}$ under reflux. Combined extracts were evaporated under reduced pressure to give a methanolic extract $(71.1 \mathrm{~g})$. A part of this extract $(69.6 \mathrm{~g})$ was extracted with hexane $(400 \mathrm{ml} \times 3)$, and the organic layer was evaporated to give a hexane soluble fraction $(17.3 \mathrm{~g})$. The hexane insoluble part was extracted with EtOAc $(300 \mathrm{ml} \times 2)$. The EtOAc insoluble part was suspended in $\mathrm{H}_{2} \mathrm{O}(500 \mathrm{ml})$ and extracted with EtOAc $(300 \mathrm{ml} \times 3)$. The EtOAc extracts were combined and evaporated to afford an EtOAc soluble fraction $(20.5 \mathrm{~g})$. The aqueous layer was evaporated followed by lyophilization to give a water soluble fraction $(21 \mathrm{~g})$. Testosterone $5 \alpha$-reductase inhibitory activity of each fraction was assayed, and the assay results are described by inhibition $\%$ in the section Results and Discussion. The EtOAc soluble fraction $(4 \mathrm{~g})$ which showed a remarkable inhibitory activity in testosterone $5 \alpha$-reductase assay was chromatographed over $240 \mathrm{~g}$ of a silica gel column $(4.5 \times 30 \mathrm{~cm})$. Elution with hexane, EtOAc and $\mathrm{MeOH}$ in increasing proportions gave 100 chromatographic fractions of $100 \mathrm{ml}$ each. TLC (hexane/ EtOAc, $1: 1)$ analysis of the collected fractions allowed us to assemble them into 10 fractions, Fr. A to J. Testosterone $5 \alpha$ reductase inhibitory activity at a concentration of $200 \mu \mathrm{g} / \mathrm{ml}$ of each fraction was assayed, and each result is indicated by inhibition \%; Fr. A [hexane/EtOAc $4: 1$ to $2: 1$, fr. No. 1 to 20 , yield; $0.4 \mathrm{~g}$, testosterone $5 \alpha$-reductase inhibition $\%$; $6.7 \%$ ], Fr. B [2: 1 to $1: 1$, fr. No. 21 to $36,0.75 \mathrm{~g}$, inhibition $\%$; 57.1\%], Fr. C [1:1, fr. No. 37 to $39,0.11$ g, inhibition $\%$; $24.4 \%$ ], Fr. D [1:1, fr. No. 40 to $41,0.03$ g, inhibition $\%$; $16.5 \%$, Fr. E [1:1, fr. No. 42 to $55,0.4 \mathrm{~g}$, inhibition $\%$; $24.3 \%$ ], Fr. F [1:1, fr. No. 56 to $58,0.15$ g, inhibition $\%$; $27.5 \%$, Fr. G $[1: 1$ to $2: 3$, fr. No. 59 to $72,0.3 \mathrm{~g}$, inhibition $\% ; 29.5 \%$, Fr. H [2:3 to $1: 2$, fr. No. 73 to $82,0.14$ g, inhibition $\% ; 21.1 \%$, Fr. I [ $1: 2$ to $\mathrm{MeOH} /$ EtOAc, $1: 1$, fr. No. 83 to $87,0.12 \mathrm{~g}$, inhibition $\% ; 3.2 \%$, Fr. J [MeOH/EtOAc, $1: 1$ to $\mathrm{MeOH}$, fr. No. 88 to $100,1.4 \mathrm{~g}$, inhibition $\%$; $13.0 \%$ ]. A mixture of active fractions, Fr. B and Fr. C, was rechromatographed over silica gel, eluted with hexane/EtOAc $(1: 1)$ and monitored with TLC (hexane/EtOAc, $1: 1$ ). Fractions showing a single spot of $R f$-value 0.6 on TLC were collected and evaporated, and the residue was recrystallized from benzene-hexane to afford $1, \mathrm{mp} 125-128^{\circ} \mathrm{C}(0.17 \mathrm{~g}$, isolation yield $0.18 \%$ ). A mixture of other active fractions, Fr. E and Fr. F, was rechromatographed over silica gel. Fractions showing a single spot of $R f$-value 0.4 on TLC were collected and evaporated, and a residue was recrystallized from EtOAc-hexane to give $2, \mathrm{mp} 81-83^{\circ} \mathrm{C}(0.15 \mathrm{~g}, 0.16 \%)$. As described in the previous paper, ${ }^{5)} \mathbf{1}$ and $\mathbf{2}$ were identified as $(-)$-cubebin and (-)-3,4-dimethoxy-3,4-desmethylenedioxycubebin, respectively.

\section{RESULTS AND DISCUSSION}

Testosterone $5 \alpha$-reductase inhibitory activities of $50 \%$ ethanolic extracts obtained from several different parts of six Piper species at concentrations of 1 and $2 \mathrm{mg} / \mathrm{ml}$ and $1 \mathrm{~mm}$ ethinylestradiol as a reference compound are shown in Table 1. Among them, the $50 \%$ ethanolic extracts obtained from $P$. 
Table 1. Inhibitory Effects of 50\% Ethanolic Extract from Piperaceae Plants and Ethinylestradiol on in Vitro Testosterone $5 \alpha$-Reductase

\begin{tabular}{|c|c|c|c|c|c|}
\hline Samples & Parts & $\begin{array}{c}\text { Yield } \\
(\%)\end{array}$ & $\begin{array}{c}\text { Final conc. } \\
(\mathrm{mg} / \mathrm{ml})\end{array}$ & $\begin{array}{c}\text { Conversion } \\
(\%)\end{array}$ & $\begin{array}{c}\text { Inhibition } \\
(\%)\end{array}$ \\
\hline Control & - & & - & $83.0 \pm 1.3$ & - \\
\hline \multirow[t]{6}{*}{ P. nigrum } & Leaf & 14.0 & 1 & $50.4 \pm 3.9^{*}$ & 39.3 \\
\hline & & & 2 & $39.0 \pm 2.3^{*}$ & 53.0 \\
\hline & Stem & 8.0 & 1 & $60.6 \pm 1.7^{*}$ & 27.0 \\
\hline & & & 2 & $49.1 \pm 2.8^{*}$ & 40.8 \\
\hline & Fruit & 4.7 & 1 & $49.9 \pm 0.4^{*}$ & 39.9 \\
\hline & & & 2 & $30.7 \pm 1.0^{*}$ & 63.0 \\
\hline \multirow{6}{*}{ P. methysticum } & Leaf & 9.3 & 1 & $71.4 \pm 0.7^{*}$ & 14.0 \\
\hline & & & 2 & $59.4 \pm 1.1^{*}$ & 28.4 \\
\hline & Stem & 14.0 & 1 & $70.7 \pm 1.8^{*}$ & 14.8 \\
\hline & & & 2 & $64.8 \pm 0.3^{*}$ & 21.9 \\
\hline & Rhizome & 8.0 & 1 & $49.2 \pm 1.5^{*}$ & 40.7 \\
\hline & & & 2 & $47.7 \pm 3.7^{*}$ & 42.5 \\
\hline \multirow[t]{2}{*}{ P. betle } & Whole plant & 25.7 & 1 & $62.8 \pm 1.8^{*}$ & 24.3 \\
\hline & & & 2 & $47.9 \pm 0.8^{*}$ & 42.3 \\
\hline \multirow[t]{8}{*}{ P. kadsura } & Leaf & 25.0 & 1 & $69.1 \pm 0.3^{*}$ & 16.7 \\
\hline & & & 2 & $67.2 \pm 3.1 *$ & 19.0 \\
\hline & Stem & 13.0 & 1 & $69.8 \pm 0.1^{*}$ & 15.9 \\
\hline & & & 2 & $69.0 \pm 2.7^{*}$ & 16.9 \\
\hline & Root & 9.3 & 1 & $62.2 \pm 1.3^{*}$ & 25.1 \\
\hline & & & 2 & $50.5 \pm 2.7^{*}$ & 39.2 \\
\hline & Rhizome & 10.3 & 1 & $60.8 \pm 0.6^{*}$ & 26.7 \\
\hline & & & 2 & $52.7 \pm 2.2 *$ & 36.5 \\
\hline \multirow[t]{2}{*}{ P. longum } & Whole plant & 9.7 & 1 & $74.5 \pm 1.7^{*}$ & 10.2 \\
\hline & & & 2 & $72.8 \pm 3.1^{*}$ & 12.3 \\
\hline \multirow[t]{2}{*}{ P. cubeba } & Fruit & 16.8 & 1 & $62.8 \pm 3.0^{*}$ & 24.3 \\
\hline & & & 2 & $28.0 \pm 3.2 *$ & 66.3 \\
\hline Ethinylestradiol & & & $1(\mathrm{~mm})$ & $30.5 \pm 1.0^{*}$ & 63.3 \\
\hline
\end{tabular}

The reaction solution contained $50 \%$ methanol extract solution $(0.2 \mathrm{ml})$ of $50 \%$ ethanolic extract; $1.0 \mathrm{ml}$ of Tris- $\mathrm{HCl}$ buffer $(\mathrm{pH} 7.2), 0.3 \mathrm{ml}$ of testosterone $(500 \mu \mathrm{g} / \mathrm{ml}$ in propylene glycol-Tris- $\mathrm{HCl}$ buffer $(1: 1 \mathrm{v} / \mathrm{v}))$, and $1.0 \mathrm{ml}$ of the enzyme solution. The reactions were started by the addition of $0.5 \mathrm{ml}$ of NADPH $(0.77 \mathrm{mg} / \mathrm{ml}$ in Tris-HCl buffer). The mixture was incubated at $37^{\circ} \mathrm{C}$ for $30 \mathrm{~min}$, and the reaction was stopped by addition of $5.0 \mathrm{ml}$ of dichloromethane. After addition of $0.5 \mathrm{ml}$ of hexyl $p$-hydroxybenzoate $(0.1 \mathrm{mg} / \mathrm{ml}$ in methanol, an internal standard (I.S.) for HPLC), the tube was shaken for $10 \mathrm{~min}$ and centrifuged at $900 \times \boldsymbol{g}$ for $10 \mathrm{~min}$. The organic layer $(4 \mathrm{ml})$ was transferred to another tube and evaporated to dryness. The residue was dissolved in $5.0 \mathrm{ml}$ of methanol, and an aliquot of $10 \mu \mathrm{l}$ was injected into the HPLC system. Each value represents from the mean \pm S.E. of 3 experiments. Significantly different from the control, $* p<0.01$

nigrum leaf, $P$. nigrum fruit, and $P$. cubeba fruit showed potent activities at a concentration of $2 \mathrm{mg} / \mathrm{ml}$. Extracts of $P$. methysticum rhizome and $P$. betle showed a moderate activity, whereas the activities of the extracts of $P$. kadsura and $P$. longum were weak.

Firstly, we targeted identification of the active principle of $P$. nigrum leaf by activity-guided fractionation of the methanolic extract of the leaves, because the activity of the methanolic extract ( $5 \alpha$-reductase inhibition $\%: 55.8 \%$ at $1 \mathrm{mg} / \mathrm{ml}$ and $91.0 \%$ at $2 \mathrm{mg} / \mathrm{ml}$ ) was superior to that of $50 \%$ ethanolic extract $(39.3 \%$ at $1 \mathrm{mg} / \mathrm{ml}$ and $53.0 \%$ at $2 \mathrm{mg} / \mathrm{ml})$. As described in the Experimental section, fractionation of the extract gave three fractions, a hexane soluble fraction, an ethyl acetate soluble fraction, and a water soluble fraction. The ethyl acetate soluble fraction ( $5 \alpha$-reductase inhibition $\%$ : $40.8 \%$ at $0.5 \mathrm{mg} / \mathrm{ml}$ and $68.1 \%$ at $1 \mathrm{mg} / \mathrm{ml}$ ) and the hexane soluble fraction $(28.3 \%$ at $0.5 \mathrm{mg} / \mathrm{ml}$ and $72.1 \%$ at $1 \mathrm{mg} / \mathrm{ml}$ ) showed significant activities, whereas the water soluble fraction $(3.1 \%$ at $0.5 \mathrm{mg} / \mathrm{ml}$ and $6.7 \%$ at $1 \mathrm{mg} / \mathrm{ml}$ ) was inactive. Activity-guided chromatography of the active ethyl acetate soluble fraction led to isolation of two active lignans, 1 and 2. ${ }^{5)}$ The main constituent of the active hexane soluble
Table 2. $\mathrm{IC}_{50}$ Values of Inhibitory Effects of Constituents from Piperaceae Plants and Ethinylestradiol on in Vitro Testosterone $5 \alpha$-Reductase

\begin{tabular}{lc}
\hline \hline \multicolumn{1}{c}{ Compound } & $\mathrm{IC}_{50}(\mathrm{mM})$ \\
\hline $\mathbf{1}$ & 0.44 \\
$\mathbf{2}$ & 1.03 \\
Piperine & 0.48 \\
Yangonin & $>10$ \\
(+)-Methysticin & $>10$ \\
Ethinylestradiol & 0.81
\end{tabular}

fraction was identified as $\mathbf{1}$ as in the previous report. ${ }^{5)}$ As shown in Table 2, the $5 \alpha$-reductase inhibitory activities of $\mathbf{1}$ $\left(\mathrm{IC}_{50}, 0.44 \mathrm{~mm}\right)$ and $2\left(\mathrm{IC}_{50}, 1.03 \mathrm{~mm}\right)$ were superior to that of ethinylestradiol ( $\left.\mathrm{IC}_{50}, 0.81 \mathrm{~mm}\right)$. Anti-inflammatory, ${ }^{14)}$ analgesic, ${ }^{15)}$ and trypanocidal ${ }^{16)}$ activities of $\mathbf{1}$ and its analogues have been known, however, the testosterone $5 \alpha$-reductase inhibitory activity of $\mathbf{1}$ has not been reported hitherto. Both leaf and stem extracts of $P$. nigrum showed similar TLC patterns in which the spots of $\mathbf{1}$ and $\mathbf{2}$ were obviously detected. Therefore, the inhibitory activity of stem extract could be attributable to $\mathbf{1}$ and analogous lignans. Since $\mathbf{1}$ is a major lignan of the fruits of $P$. cubeba, ${ }^{17)}$ the inhibitory activity of $P$. cubeba fruit extract may be attributable to $\mathbf{1}$.

Secondly, we studied in vitro testosterone $5 \alpha$-reductase inhibitory activities of other known constituents of the cited Piper species. Fruits of $P$. nigrum contain piperine as a major alkaloid amide ${ }^{18)}$ and a considerable amount of fatty acids such as linoleic, oleic and palmitic acids. ${ }^{19)}$ Piperine showed a potent testosterone $5 \alpha$-reductase inhibitory activity $\left(\mathrm{IC}_{50}\right.$, $0.48 \mathrm{~mm}$, Table 2). Gastroprotective, ${ }^{20)}$ monoamine oxidase inhibitory, ${ }^{21)}$ anticonvulsive, ${ }^{22)}$ and other many activities of piperine have been previously reported, but the testosterone $5 \alpha$-reductase inhibitory activity of piperine was found here for the first time. We have reported that several fatty acids showed testosterone $5 \alpha$-reductase inhibitory activity, and that $\mathrm{IC}_{50}$ values of oleic, linoleic and palmitic acids were 0.44 , 0.37 , and $1.35 \mathrm{~mm}$, respectively. ${ }^{12}$ ) Thus, it is suggested that the inhibitory activity of $P$. nigrum fruit extract may be attributable to its major constituents, piperine and fatty acids such as linoleic, oleic and palmitic acids. As to P. methysticum rhizome (Kava), we have isolated five kavalactones, yangonin, (+)-methysticin, (+)-kawain, 5,6-dehydrokawain, and 7,8epoxyyangonin, from Kava extract. ${ }^{7)}$ None of these kavalactones showed significant $5 \alpha$-reductase inhibitory activity. The $\mathrm{IC}_{50}$ value of yangonin and $(+)$-methysticin, major kavalactones of $P$. methysticum rhizome, was more than $10 \mathrm{~mm}$. It is considered that the moderate inhibitory activity of $P$. methysticum rhizome extract depends not on the cited kavalactones, but on other unidentified constituents.

Thirdly, we examined in vivo anti-androgenic activity of the methanolic extract of $P$. nigrum leaf by using the hair regrowth assay in testosterone sensitive male C57Black/6CrSlc strain mice. In this experimental model animal, it has been noted that testosterone caused a disorder in the stage of terogen during the course of the hair growth cycle in dermal papilla cells. ${ }^{1)}$ As shown in Fig. 2, testosterone treatment caused a remarkable suppression of hair regrowth in mice. Topical application of 5\% solution of the methanolic extract of $P$. nigrum leaf showed a significant anti-androgenic activity (Fig. 2B) as did oxendolone (Fig. 2A), a positive refer- 
ence drug, as described in the previous paper. ${ }^{12)}$ Thus, it was revealed that the $P$. nigrum leaf extract showed a significant anti-androgenic activity in the in vivo hair regrowth assay using C57Black/6CrSlc strain mice.

In conclusion, these findings led to an interesting fact that the extract of $P$. nigrum leaf and its two lignans, $\mathbf{1}$ and $\mathbf{2}$, exhibited both testosterone $5 \alpha$-reductase inhibitory activity and melanogenesis stimulation activity. It is suggested that the extract of $P$. nigrum leaf is a desirable hair-care cosmetic material for prevention of gray hair and alopecia.

Acknowledgements This work was financially supported by the "High-Tech Research Center" Project for Private Universities: matching fund subsidy from MEXT (Ministry of Education, Culture, Sports, Science and Technology) of Japan, 2007-2011.

\section{REFERENCES}

1) Randall V. A., Thornton M. J., Hamada K., Redfern C. P. F., Nutbrown M., Ebling F. J. G., Messenger A. G., Ann. N.Y. Acad. Sci., 642, 355375 (1991).

2) Hamilton J. B., Amer. J. Anat., 71, 451-480 (1942).

3) Tobin D. J., Paus R., Exp. Gerontol., 36, 29-54 (2001).

4) Horikawa T., Norris D. A., Johnson T. W., Zekman T., Dunscomb N., Bennion S. D., Jackson R. L., Morelli J. G., J. Invest. Dermatol., 106, 28-35 (1996).

5) Matsuda H., Kawaguchi Y., Yamazaki M., Hirata N., Naruto S., Asanuma Y., Kaihatsu T., Kubo M., Biol. Pharm. Bull., 27, 1611-
1616 (2004).

6) Matsuda H., Hirata N., Kawaguchi Y., Yamazaki M., Naruto S., Shibano M., Taniguchi M., Baba K., Kubo M., Biol. Pharm. Bull., 28, 1229-1233 (2005).

7) Matsuda H., Hirata N., Kawaguchi Y., Naruto S., Takata T., Oyama M., Iinuma M., Kubo M., Biol. Pharm. Bull., 29, 834-837 (2006).

8) Imai Y., Protein Nucleic Acid Enzyme, 10, 170-180 (1965).

9) Ibata Y., J. Soc. Cosmet. Chem. Japan, 92, 78-83 (1988).

10) Matsuda H., Yamazaki M., Matsuo K., Asanuma Y., Kubo M., Biol. Pharm. Bull., 24, 259-263 (2001).

11) Matsuda H., Sato N., Yamazaki M., Naruto S., Kubo M., Biol. Pharm. Bull., 24, 586-587 (2001).

12) Matsuda H., Yamazaki M., Naruto S., Asanuma Y., Kubo M., Biol. Pharm. Bull., 25, 622-626 (2002).

13) Yokoyama D., Fragrance J., 27, 50-56 (1999)

14) Bastos J. K., Calvalho J. C. T., Souza G. H. B., Pedrazzi A. H. P., Sarti S. J., J. Ethnopharmacol., 75, 279-282 (2001).

15) Borsato M. L. C., Grael C. F. F., Souza G. E. P., Lopes N. P., Phytochemistry, 55, 809-813 (2000).

16) Bastos J. K., Albuquerque S., Silva M. L. A., Planta Med., 65, 541544 (1999).

17) Prabhu B. R., Mulchandani N. B., Phytochemistry, 24, 329-331 (1985).

18) Semler U., Gross G. G., Phytochemistry, 27, 1566-1567 (1988).

19) Daulatabad C. D., Mulla G. M., Mirajkar A. M., Fat Sci. Technol., 97, 453-454 (1995).

20) Morikawa T., Matsuda H., Yamaguchi I., Pongpiriyadacha Y., Yoshikawa M., Planta Med., 70, 152-159 (2004).

21) Lee S. A., Hong S. S., Han X. H., Hwang J. S., Oh G. J., Lee K. S., Lee M. K., Hwang B. Y., Ro J. S., Chem. Pharm. Bull., 53, 832-835 (2005).

22) Pei Y. Q., Epilepsia, 24, 177-182 (1983). 